\title{
A NOÇÃO DE PSICOPATOLOGIA: DESDOBRAMENTOS EM UM CAMPO DE HETEROGENEIDADES ${ }^{1}$
}

FERNANDA CESA FERREIRA DA SILVA MORAES \& MÔNICA MEDEIROS KOTHER MACEDO

\section{Fernanda Cesa \\ Ferreira da Silva \\ Moraes}

Pontifícia Universidade Católica do Rio Grande do Sul (PUCRS), professora no curso de Psicologia da Escola de Saúde, Porto

Alegre/RS, Brasil.

\section{Mônica Medeiros} Kother Macedo

Pontifícia Universidade Católica do Rio Grande do Sul (PUCRS), doutora pelo Departamento de Psicologia, Porto Alegre/RS, Brasil.

\begin{abstract}
RESUMO: A psicopatologia configura-se como um conceito amplo e complexo. Na tentativa de contemplar a diversidade e as divergências próprias à temática, é efetuada uma trajetória que enfatiza concepções relacionadas às origens e aos significados atribuídos às afecções mentais. As distintas concepções destes padecimentos resultam, ao longo da história, no emprego de terapêuticas heterogêneas. Diante da constatação contemporânea de um retorno à valorização das explicações etiológicas de cunho organicista e da medicalização como terapêutica princeps frente às patologias psíquicas, apresenta-se a psicanálise como uma disciplina que explicita importante ruptura epistemológica e consequente diversidade na concepção de psicopatologia e sua terapêutica.
\end{abstract}

Palavras-chave: psicopatologia; afecções mentais; psicanálise.

\begin{abstract}
The notion of psychopathology: developments in an heterogeneity field. Psychopathology is a broad and complex concept. In an attempt to encompass the diversity and differences inherent to this subject, this narrative review emphasizes concepts related to the origins and meanings attributed to mental disorders. The distinct conceptions of these sufferings result, throughout history, in the use of heterogeneous therapeutics. In this respect, different forms of addressing these concepts throughout the history are explored, as well as the consequences of these concepts on the treatment employed. Given the current return to the appreciation of etiological explanations that are organismic in nature and medicalization as the foremost therapy ahead of psychic pathologies, psychoanalysis is presented as a discipline that explains an important epistemological rupture and consequent diversity in the concept of psychopathology and its treatment.
\end{abstract}

Keywords: psychopathology; mental disorders; psychoanalysis.

DOI - http://dx.doi.org/10.1590/1809-44142018001008

\footnotetext{
${ }^{1}$ Este artigo integra uma tese de doutorado desenvolvida no Programa de Pós-Graduação em Psicologia da Pontifícia Universidade Católica do Rio Grande do Sul (PUCRS), sob orientação da profa doutora Mônica Medeiros Kother Macedo.
} 


\section{INTRODUÇÃO}

Inegavelmente, o tema das afecções próprias ao campo mental articula-se com a própria história da humanidade, uma vez que as tentativas de compreensão sobre a temática são realizadas desde a Antiguidade. Pessoti (1995) afirma que, ao longo das épocas, as sucessivas concepções de loucura (ou denominações que equivalham ao termo, como alienação, doença mental, transtorno mental ou sofrimento psíquico, entre outras) apresentam conteúdos relativamente permanentes, porém, também contemplam conceitos que se mostram inconciliáveis. Esta condição de heterogeneidade conceitual das afeç̧ões mentais leva à necessidade de considerar as particularidades de cada período histórico e de cada escola de pensamento, pois, segundo Gabbay e Vilhena (2010), o mundo e as mentalidades mudam de acordo com as transformações políticas, econômicas e sociais de cada época.

Conforme Ceccarelli (2005), cada contexto histórico-político teve a sua definição de psicopatologia, sendo que tal afirmativa pode ser visualizada nas diversas tentativas, ao longo dos tempos, de decompor o sofrimento emocional em seus elementos de base para buscar compreendê-los, estudá-los e tratá-los. Assim, considerando a relação inegável entre o sujeito e as demandas do tempo que habita, toma-se como eixo norteador de análise, neste artigo, a proposição de Freud (1929 [1930]/1996) sobre somente ser possível avaliar o pathos a partir dos elementos do imaginário social da cultura no qual o padecimento psíquico emerge.

Logo, a psicopatologia configura-se como um conceito amplo e complexo, que pode ser compreendido por vários ângulos e direções, incluindo distintas disciplinas além das "psi", tais como sociologia, direito, filosofia, história, entre outras. Esses saberes, embora não necessariamente reconhecidos pelo domínio e propriedade na abordagem deste assunto, contribuem significativamente para a compreensão dos vários espectros do conceito. Essa pluralidade conceitual, porém, não pode ser confundida com uma mistura equivocada de teorias, evidenciando-se a necessidade de que se assuma qual concepção teórica sustenta a definição do sofrimento emocional utilizada.

Na tentativa de explicitar a amplitude do tema, e no intuito de contemplar a diversidade e as divergências próprias ao campo de conceitualização de patologia mental, respeitando-se as fronteiras teóricas e epistemológicas existentes, recorre-se a um percurso histórico referente à sua compreensão e suas terapêuticas. Busca-se, nesta revisão narrativa, enfatizar algumas concepções relacionadas às origens e aos significados atribuídos às afecções mentais, bem como abordar distintas formas de tratá-las ao longo da história. Situa-se a importante ruptura provocada pela psicanálise frente ao paradigma consciencialista muitas vezes vigente, enfatizando, assim, a relevância de contemplar a singularidade do sujeito em sua produção psicopatológica. Não se pretende, porém, esgotar a complexidade da temática. Ao contrário, elegem-se elementos que possibilitem a problematização da noção de psicopatologia de forma a aproximá-la às diferentes ferramentas contemporâneas de leitura do padecimento psíquico.

\section{ACEPÇÕES ACERCA DA PATOLOGIA MENTAL: DO MÍTICO RELIGIOSO AO ANATOMOFISIOLÓGICO}

Encontram-se diversos registros acerca das afeç̧ões mentais e, também, dos efeitos inquietantes provocados por tais manifestações humanas. Retomando a Grécia antiga, encontram-se textos das tragédias gregas nos quais a loucura é apresentada e comentada, na tentativa de encontrar explicações para tais desvios, conforme assinala Pessotti (1994). Esses textos trágicos não necessariamente pretendem compreender a psicopatologia humana, mas, sim, retratar a vida cotidiana com seus dramas e aberrações. Para Ceccarelli (2005), a loucura é exposta na tragédia grega como uma impossibilidade de escolha individual diante dos conflitos entre as paixões, as lealdades e os deveres impostos pelo destino. Vale ressaltar que o destino, a partir da crença característica da época, era imposto pelos deuses. O papel do homem era o de ser objeto inerte e passivo, comandado pelas divindades, seres de supremos poderes que conduziam todas as coisas a seus resultados. 
Nesta época, a concepção de natureza humana era fragmentada, conforme caracteriza Pessotti (1994). O homem era composto pelo thymos e pela psyque. Cabia ao thymos, uma espécie de alma funcional que presidia as relações do organismo com o meio externo, ser responsável pelas atividades de aprendizagens, motivações, memórias, sensações e emoções. Já a psyque era considerada como o verdadeiro espírito que habita o homem, pois se trataria da alma que deixa o corpo material após a morte. $O$ ser humano, equipado de thymos e psyque, não seria autônomo, pois suas capacidades motoras, perceptivas e mentais estavam, permanentemente, sob o controle superior e transcendental.

Entretanto, Pessotti (1994) ressalva que este controle era supostamente realizado por deuses dotados de caprichos, vaidades e ambições, os quais podiam se mostrar desmedidos e insensatos, provocando um controle arbitrário, confuso e ilógico. Logo, os homens podiam manifestar perda ou turvamento temporário da razão como um estado de espírito que era ocasionado, invariavelmente, por uma divindade. 0 sofrimento humano era compreendido, então, como obra dos deuses. Na Grécia antiga, a loucura era concebida como um estado de desrazão e de perda de controle, um castigo decorrente da irritação dos deuses com o descomedimento humano.

A partir desta concepção mitológica, Pessotti (1994) afirma que o pecado fundamental e a origem dos males humanos decorriam da empáfia do homem em buscar superar ou transgredir o próprio destino, com a pretensão de se aproximar ou se assemelhar aos deuses. Assim, por ser obra divina, a loucura era apenas um estado de espírito derivado de uma interferência transitória transcendental, pois, quando o humor da divindade melhorasse, a loucura e seus efeitos desapareceriam. Já no que tange às terapêuticas, havia a menção do uso de um pharmakon, ou seja, uma bebida misteriosa que conduzia ao esquecimento, acalmava as aflições, atenuava a ansiedade e poderia induzir à aceitação tranquila da sentença dos deuses (CECCARELLI, 2005).

Neste contexto, destacam-se concepções oriundas de Platão e Sócrates, que ressaltaram a existência de uma forma de loucura tida como divina e, inclusive, utilizavam a mesma palavra, manikê, para designar tanto o "divinatório" como o "delirante" (SILVEIRA; BRAGA, 2005). Segundo os filósofos, era por meio do delírio que alguns humanos privilegiados podiam ter acesso a verdades divinas. Logo, a desrazão manifestada por essas pessoas as tornava especiais e sagradas.

Ainda na Grécia antiga, o modelo mítico-teológico começa a ser substituído por uma visão mais racionalista sobre as contradições, limitações e fraquezas humanas (CECCARELLI, 2005). A concepção de Hipócrates, em meados de 400 a.C., afasta a influência divina na loucura, a qual passa a ser vista como uma doença e percebida como um efeito do desarranjo da natureza orgânica do homem. Assim, os processos de perda de razão ou do controle emocional constituem efeitos de tal desarranjo. A proposta de Hipócrates denota uma visão organicista da afecção, pois a origem da loucura deveria ser buscada nas disfunções humorais. Volich (2000) refere que Hipócrates, na tentativa de explicar os estados de enfermidade e saúde, postulou a existência de quatro fluidos (humores) no corpo: bile amarela, bile negra, fleuma e sangue. A saúde era baseada no equilíbrio entre os quatro elementos. $O$ homem era visto como uma unidade organizada e a doença era tida como uma desorganização deste estado. Tais ideias, segundo Ceccarelli (2005), tiveram importante influência nos séculos XVIII e XIX, oferecendo as primeiras concepções científicas à medicina.

$\mathrm{Na}$ concepção de Hipócrates, o cérebro era o órgão de etiologia da loucura, uma vez que, lesado pelos desequilíbrios humorais derivados da umidade gerada pela fleuma ou pela bílis, provocava a patologia. Cada um dos humores era responsável por um tipo de loucura diferente: melancolia ou mania. Hipócrates foi, portanto, o precursor da distinção clínica e etiológica entre os dois tipos clássicos de loucura, conforme destaca Pessotti (1994). $O$ autor refere que a vida psíquica foi reduzida às funções de um órgão, uma vez que se equivale a saúde mental à "saúde do encéfalo" (ibidem, p. 52). As terapêuticas decorrentes da doutrina hipocrática baseavam-se no rearranjo humoral através da katársis, ou seja, da expulsão das substâncias em 
desequilíbrio e da limpeza de um organismo ou de um órgão específico. As intervenções focavam em alterações no regime alimentar ou nos hábitos cotidianos, a fim de reestabelecer o equilíbrio nos humores.

Pode-se considerar que a doutrina hipocrática, ao enfatizar apenas o organicismo na etiologia da loucura, acabou por postergar explicações que abarcassem elementos psíquicos e que, desta forma, conduzissem a uma "psicoterapia" (PESSOTTI, 1994, p. 51). Cabe, porém, destacar o mérito de Hipócrates em compreender a loucura, aproximando-a de uma sistemática investigativa distante de crenças míticas ou religiosas.

Cláudio Galeno, no segundo século da era cristã, mesclou e integrou as ideias de Platão e de Hipócrates em sua visão de saúde-doença (CECCARELLI, 2005). Alinhado à cultura judaico-cristã, Galeno supunha a existência da alma; entretanto, mesmo que a alma fosse responsável por comandar o corpo, ela transcendia a ele. Pessotti (1994) sustenta que a teoria galeniana fundamentou a existência de uma dualidade alma-corpo, ou mente-corpo, pois propunha o funcionamento de um pneuma psíquico, que era produzido no cérebro e comandava as atividades mentais e nervosas. Essa formulação institui "a identidade de funções psíquicas" (ibidem, p. 77). Assim, o psíquico adquiriu uma identidade própria, pois antes era considerado apenas como um reflexo dos eventos somáticos. Mesmo sendo ainda bastante organicista, esta teoria realizou uma abertura para os conceitos psicológicos, na qual "a localização das faculdades mentais numa mesma sede pode ser vista como uma semente da ideia de um aparelho psíquico" (ibidem, p. 77), como descrito por Sigmund Freud no final do século XIX.

No período medieval, constata-se o retorno à concepção mítico-religiosa do passado na forma de compreender as manifestações humanas consideradas anormais, insensatas ou insanas. A loucura e a pobreza eram compreendidas igualmente, como um purgatório terreno e um desígnio de Deus. Para alcançar a purificação espiritual, era necessário aceitar os desígnios e assumir seu fardo. Nesse período, a perda da razão ou o descontrole emocional assumem a marca da condenação e da culpa (PESSOTTI, 1994). Como o homem era considerado um ser passivo, a culpa que lhe era atribuída se relacionava à fraqueza, própria daqueles que eram tentados pelas forças do mal. Para Cherubini (2006), o louco passa a ser visto como perigoso, pois a possessão demoníaca só ocorreria em pessoas que estivessem em falta, levando em consideração a crença de que os bons não seriam atingidos pelo demônio. Para a autora, este foi o início da sustentação da periculosidade dos loucos, que logo após fundamentou a sua constrição através de medidas de segurança e da exclusão social.

Apesar de constatarem que desde a Idade Média já existiam mecanismos de exclusão do louco, Silveira e Braga (2005) salientam que a loucura não era percebida como um fenômeno que requeria um saber científico específico. Os primeiros estabelecimentos criados (asilos, hospitais e leprosários) para circunscrever a loucura destinavam-se simplesmente a retirar do convívio social as pessoas que não se adaptavam a ele. Aliava-se, por exemplo, a "loucura" à temível doença da época, a lepra. Apenas no período histórico seguinte identificaram-se indícios de transformação na estigmatização da loucura.

No século XVI, frente ao declínio do poder da Igreja, surgem teorias explicativas, ocorrendo a derrubada das verdades absolutas aceitas até o momento. Alberti e Fulco (2005) observam a importância do aparecimento das teorias renascentistas sobre o Universo e o Homem. O início da investigação científica se deu a partir da dissociação entre influências teológicas e investigação da realidade. A corrente filosófica do racionalismo propunha que a verdade devia ser alcançada por meio da razão e não da fé, defendendo a ideia de que a razão possibilitaria ao ser humano compreender e controlar a natureza.

Diante da incerteza quanto à realidade do mundo objetivo - em função do corte com o dogmatismo religioso -, Descartes afirma a certeza do cogito - Penso, logo existo. O homem existe porque é possível inscrevê-lo no simbólico, no pensamento que lhe dá uma morada no cogito. Descartes distinguiu um mundo em que as coisas existem através de sua representação conceitual, deixando de fora outro mundo onde as coisas não são conceituadas. Era então a criação de um novo discurso: o da ciência. (ALBERTI; FULCO, 2005, p. 722) 
A noção de psicopatologia: desdobramentos em um campo de heterogeneidades

No célebre Discurso sobre o método, em 1637, Descartes propôs a razão na busca da verdade para fazer ciência. Apesar de introduzir o método científico e de se afastar das concepções místicas sobre o mundo, Descartes segue afirmando a existência de Deus como um fiador para o pensamento humano, ou seja, algo metafísico que oferecia coerência ao cogito. Seu texto sustenta o paradigma matemático como diretriz do pensamento, almejando a certeza e a eliminação de dúvidas. Segundo Alberti e Fulco (2005), Descartes concebeu a realidade composta de duas áreas distintas e separadas: o domínio físico, da matéria; e o reino imaterial da mente. Apesar da nova proposta, as considerações de Descartes sobre o dualismo não esclareceram a natureza da relação entre o corpo e a alma. A dúvida sobre como e por que tais substâncias se combinam para formar o homem mantem-se desde então, norteando debates entre diversas teorias. Para Descartes, o "eu" seria a consciência, uma substância pensante, considerando a subjetividade composta por ideias e princípios inatos. O "eu", como entidade racional, estaria apto a descobrir as verdades (GABBAY; VILHENA, 2010).

Uma vez que o "eu" associado à loucura não estava amparado na razão, em um contexto que sustentava a primazia do pensamento e, logo, da consciência, os loucos ficavam à margem, excluídos das novas perspectivas que se vislumbravam na cena social. Foucault (1978) sustenta que a loucura, mais enfaticamente no século XVIII, foi associada à marginalidade humana, já que muitas pessoas nessas condições assumiam o comportamento de animais e, portanto, deveriam ser tratadas como tais. Estas manifestações passam, então, a ser vistas como uma forma de alienação das regras sociais. Nesse contexto, ocorreu o movimento social do denominado "Grande Confinamento", no qual os membros da sociedade que eram considerados irracionais foram encarcerados e institucionalizados em asilos. Destaca-se que esse momento histórico, marcado por acelerada urbanização e crescente industrialização no mundo do trabalho, favoreceu o confinamento da loucura, em decorrência da inadaptação do louco diante das mudanças e de sua incômoda presença na paisagem social (FOUCAULT, 1978).

Ainda no século XVIII, no cenário dessas instituições fechadas, as concepções de psicopatologia eram desordenadas, baseadas em uma visão organicista que não se fundamentava em bases empíricas (PESSOTTI, 1994). Os critérios de descrição e categorização das manifestações atribuídas à loucura eram desorganizados e diferentes entre si, pois se vinculavam a avaliações de determinadas autoridades médicas. A partir do século XIX, a explosão taxionômica iniciada nas ciências naturais - a própria medicina, por meio da anatomia patológica da fisiologia - procurou reduzir o homem a um objeto cientificamente investigável (ALBERTI; FULCO, 2005). Surgiu a preocupação com as relações de causa e efeito, fazendo da medicina uma prática guiada pelo princípio da causalidade.

No início do século XIX o médico Phillippe Pinel lança o Tratado médico-filosófico sobre a alienação mental, modificando radicalmente a visão da loucura e inaugurando uma nova especialidade médica: a psiquiatria (CECCARELLI, 2005). A contribuição de Pinel significou a submissão do fenômeno da loucura à racionalidade médica. Ao contrário de Descartes, que afirmava a incompatibilidade radical entre a razão e loucura, alijando o louco da espécie dos racionais, Pinel concebia a loucura como uma contradição no interior da própria razão. Logo, uma parcela de razão se mantinha preservada mesmo nos estados de alienação. Os loucos passam a ser chamados de alienados e de doentes, sendo a loucura uma doença manifestada pelo desequilíbrio na razão ou nos afetos (GABBAY; VILHENA, 2010).

Destaca-se a primeira atribuição de importância aos afetos na teorização sobre a loucura. A desrazão foi concebida, para Pinel, como uma expressão das paixões dos sujeitos e de seus excessos emocionais (PEREIRA, 2004). A segunda edição do tratado refere que o conceito de alienação associa-se à causa que mais frequentemente a provoca, ou seja, o afeto derivado das "paixões violentas ou exasperadas pelas contradições" (PESSOTTI, 1994, p. 145).

Em relação às práticas terapêuticas, Gabbay e Vilhena (2010) afirmam que Pinel foi um divisor de águas na história da loucura, reinventando o manicômio como um local de tratamento. Para Pinel "os alienados 
eram doentes cujo doloroso estado merecia toda a consideração devida à humanidade que sofre e para quem se deve buscar, pelos meios mais simples, restabelecer a razão desviada" (PEREIRA, 2004, p. 114).

Ao oferecer tratamento, Pinel inaugura um olhar sustentado por novas práticas diante dos padecimentos emocionais, considerando o passado como uma era de crendices e superstições, baseado na irracionalidade (GABBAY; VILHENA, 2010). Pinel, juntamente com seus discípulos, buscou aplicar ao campo mental o imperativo da ordem e da investigação que dominava todas as partes da história natural, fundando as bases de um tratamento médico estabelecido unicamente na observação e na experiência. Os sintomas deveriam ser observados com atenção e empenho constantes, identificados e classificados com base na referência à faculdade (intelecto, vontade e afetividade, entre outras) comprometida. A inovação teórica proposta por ele consistia na ideia de que a essência da loucura residiria no desarranjo das funções psíquicas ou mentais, ainda que eventualmente causado por fatores orgânicos ou associado ao sistema nervoso. Conforme Gabbay e Vilhena (2010), a partir do tratado, o termo psicopatologia adquiriu o significado de teoria da loucura. Pinel estabeleceu uma distância metodológica entre a observação dos fenômenos e o esboço de uma explicação para eles, originando a clínica dessas patologias. $O$ tratamento, caracterizado como moral, era essencialmente pedagógico e fundava-se na premissa de que seria possível alcançar mudanças significativas no comportamento dos doentes se a equipe técnica os reeducassem por meio de atitudes firmes, sendo que termos como "repressão", "intimidação", "docura" e "filantropia" passaram a ser encontrados cotidianamente no vocabulário técnico daquele cenário (PEREIRA, 2004).

Das teorias de Pinel, depreende-se que o louco não é essencialmente diverso do homem sadio, pois qualquer um pode ser indiferente à razão ou ao bom senso. Seguindo os passos de Pinel, outros médicos continuaram se debruçando sobre as manifestações psicopatológicas do homem, com a vigente preocupação de conhecer e classificar a sintomatologia das doenças a partir do rigor da observação, de forma sistemática e minuciosa. Para Ceccarelli (2005), o aparecimento da psicopatologia como disciplina organizada se deu a partir da publicação do livro Psicopatologia geral, de Karl Jaspers, em 1913. Conforme Rodrigues (2005), Jaspers interessava-se em garantir à psicopatologia a ancoragem empírica em dados passíveis de observação por qualquer um, e não em construções que, embora coerentes, tivessem origem teórica e não prática. Também se destacou neste âmbito o psiquiatra Emil Kraepelin, que desenvolveu princípios sobre a classificação das doenças mentais. Kraepelin construiu um modelo nosográfico de psicopatologia, criando categorias baseadas na sintomatologia, na evolução e no prognóstico de cada entidade clínica isolada. A partir do que denominou de psiquiatria comparativa, buscava "isolar o núcleo mórbido propriamente médicobiológico da loucura de suas expressões visíveis transformadas pela cultura, pela história e pela subjetividade" (PEREIRA, 2009, p. 162).

Apesar do empenho demonstrado na compreensão das patologias mentais e das tentativas terapêuticas que almejavam alguma cura, percebia-se que os loucos seguiam encarcerados em instituições, as quais não traziam nenhuma resolutividade para as sintomatologias que se faziam presentes. Roudinesco (2009) constata que a lógica inerente ao desejo de classificação da psiquiatria e da busca anatômica das doenças mentais gerou, como consequência, a ideia de cronicidade e incurabilidade devido ao confinamento perpétuo nos manicômios. Para a autora, os tratamentos eram reduzidos ao niilismo terapêutico, já que não alcançavam nenhuma melhora ao asilado e portador de doença mental.

É neste contexto de questionamentos e descobertas a respeito das patologias ditas "mentais" que surgem, no final do século XIX e início do século XX, as proposições de Sigmund Freud, criador da psicanálise. Roudinesco (2009) sustenta que a psicanálise "nasceu das ruínas de um sistema de pensamento que havia posto o hospício, a filantropia, a cura e depois a incurabilidade no cerne de suas preocupações ao preço de afogar a subjetividade na organogênese" (p. 219). Ao nascer, a doutrina psicanalítica provocou importantes transformações na forma de concepção e terapêutica das patologias psíquicas. 
A noção de psicopatologia: desdobramentos em um campo de heterogeneidades

\section{A SINGULARIDADE DA NOÇÃO DE SUJEITO E DE PATOLOGIA NA PSICANÁLISE}

Apesar do reconhecimento do importante passo dado por Pinel no sentido de postular um resto de razão na loucura, seu avanço não pode ser confundido com a revolução feita por Freud mediante sua concepção do sujeito psíquico. Se, em Pinel, há a concepção de um resto de razão apesar da loucura, em Freud se buscará encontrar uma razão na loucura (GABBAY; VILHENA, 2010).

Considerando-se os postulados racionalistas da doutrina cartesiana, a qual concebia o sujeito atrelado à certeza do cogito e do predomínio de uma visão consciencialista, pode-se constatar a dimensão da ruptura epistemológica causada com o advento da psicanálise. Freud rompe com este paradigma consciencialista ao afirmar ser o sujeito regido pelo inconsciente. Se, em Descartes, o sujeito era traduzido por "penso, logo existo", em Freud pode-se caracterizar o sujeito, conforme a proposição lacaniana, como "penso onde não sou, logo, sou onde não penso" (GABBAY; VILHENA, 2010, p. 47).

Segundo Gabbay e Vilhena (2010), Freud causou uma verdadeira ferida narcísica na humanidade ao propor a ideia do inconsciente e, assim, um descentramento do próprio sujeito. Dockhorn e Macedo (2008) demarcam que, ao apresentar o inconsciente, Freud retira a patologia do campo físico, sustentando que o psíquico não se equivale à consciência. Na época, o inconsciente teria sido justificado nas evidências de inúmeras lacunas entre os conteúdos da consciência, atribuindo-se sua existência e suas manifestações nos indivíduos sadios e enfermos.

Na vigência da observação como uma ferramenta para o processo de compreensão das manifestações psicopatológicas, Freud acompanha o neurologista Charcot em seus estudos sobre a hipnose e na proposição de um diagnóstico diferencial entre a histeria a as patologias de cunho neurológico. Opondo-se à ideia de que a histeria era uma doença eminentemente feminina, o método de Charcot implicava tornar visíveis os sintomas para, posteriormente, tentar estabelecer a localização de uma lesão correspondente no sistema nervoso (FULGÊNCIO, 1998).

A partir das experiências obtidas com Charcot, Freud inicia seu exercício na clínica da histeria. Destacase que Freud não apenas reproduziu os ensinamentos adquiridos, pois introduziu uma grande modificação no tratamento da histeria e demais neuroses, realizando um deslocamento do olhar para a escuta, alterando significativamente a maneira do médico se relacionar com o paciente. Berlinck (2008) refere que "a primazia da escuta deixa de lado a visibilidade controlada da dor para se interessar pelos mecanismos que a provocam" (p. 324).

Freud consolida, cada vez mais, sua concepção teórica e suas proposições técnicas enfatizando o valor da singularidade no alcance do método da psicanálise, afirmando que cada sujeito tem algo único a dizer ao analista sobre seu padecimento. A escuta psicanalítica, em sua especificidade técnica e terapêutica, promoveu uma revolução na ciência da época. Para Berlinck (2008), a escuta desenvolvida nessa modalidade de exercício clínico originou-se na convicção de que a doença psíquica continha um ensinamento que não poderia ser apreendido pelo método experimental, mas somente pela escuta e pelo trabalho interpretativo a partir de rememorações e da transferência posta em cena pelo sujeito.

Considerando as divergências metodológicas apresentadas, e diante das imposições experimentais na construção de conhecimento, Freud se viu impelido a construir um arcabouço conceitual consistente para embasar suas proposições acerca dos conteúdos psíquicos e das suas inovações clínicas no tratamento da histeria. Sendo assim, Freud inaugura sua metapsicologia, definida como a descrição dos processos psíquicos nas suas relações dinâmicas, tópicas e econômicas, a partir de princípios, conceitos fundamentais e modelos teóricos que esclarecem e aprofundam as hipóteses subjacentes à psicologia psicanalítica (LAPLANCHE; PONTALIS, 2000). O termo "metapsicologia" refere-se à originalidade de estruturar uma psicologia que se opusesse às correntes, vigentes na época, de uma psicologia da consciência, eminentemente experimental e organicista. 
A psicanálise, portanto, é a disciplina fundada por Freud que apresenta três pilares: um método de investigação do inconsciente, uma técnica de tratamento e um conjunto sistematizado de teorias psicológicas e psicopatológicas (FREUD, 1923 [1922]/ 1996). A partir de sua singular concepção de sofrimento psíquico e da consideração à etiologia não linear ou consciencialista, a condição de sujeito e a compreensão de seus padecimentos são redimensionados. Não se trata de desconsiderar a existência do que está posto como biológico e inato, mas, sim, de lançar o olhar àquelas configurações psíquicas decorrentes dos efeitos singulares do experienciado pelo sujeito de inconsciente.

O cenário da modernidade passa a ser explorado por Freud (1908/1996) para além das expressões psicopatológicas decorrentes da intensa repressão à sexualidade feminina. Seus pressupostos detalham o peso da moral civilizatória, o mal-estar que predomina naquele cenário histórico, mas, sobretudo, aborda o efeito singular de tais demandas em relação ao sujeito de inconsciente e de sexualidade. Desde o início de sua obra, Freud não se limitou a uma concepção de padecimento psíquico no modelo da causalidade linear ou preconcebida e, tampouco, que desimplicasse o sujeito de sua produção sintomática. A psicanálise toma o sintoma em seu aspecto manifesto apenas como ponto de partida de um percurso que tem como meta adentrar a complexidade de processos psíquicos presentes na singular condição de sofrimento.

A psicopatologia significa, para a psicanálise, conforme Berlinck (2008), "um sofrimento, uma paixão, uma passividade que porta em si mesmo a possibilidade de um ensinamento interno" (p. 21). O sujeito se mostra passivo diante do excesso de sofrimento e do desequilíbrio de suas emoções, porém também se apresenta ativo na produção de sua sintomatologia e, por conseguinte, na sua manifestação psicopatológica. O encontro analítico permitirá que o discurso do sujeito, que narra o seu pathos, possa ser escutado e pensado, transformando-o em experiência enriquecedora de conhecimento sobre si mesmo (BERLINCK, 2008).

A concepção de padecimento psíquico é problematizada na psicanálise ao trazer a debate as relações estabelecidas entre o sujeito e a cultura. Se a modernidade contribuiu significativamente para o nascimento desta disciplina, a contemporaneidade segue demandando uma necessária inclusão dos fatores psíquicos descritos pela psicanálise para a aprofundada compreensão das complexas demandas de sofrimento da atualidade.

No que tange à cultura, Birman (2012) observa que dor e sofrimento não são formas a-históricas de sentir, pois estão atreladas às marcas antropológicas nas subjetividades de cada contexto. Assim, remetendose às transformações evidenciadas nas manifestações de mal-estar na contemporaneidade, o autor afirma que essas se caracterizam fundamentalmente pela dor e não pelo sofrimento, pois as narrativas clínicas atuais denotam que "no lugar das antigas modalidades de sofrimento centradas no conflito psíquico, nas quais se opunham os imperativos dos impulsos e os das interdições morais, o mal-estar agora se evidencia nos registros do corpo, da ação e do sentimento" (BIRMAN, 2012, p. 174). O corpo parece ser o único bem para os sujeitos do mundo contemporâneo. Entretanto, há uma queixa geral de que o corpo não funciona a contento e que sua performance sempre pode melhorar.

As pessoas vivem preocupadas com o que falta na saúde e no corpo, bem como com os cuidados que, incontestavelmente, devem conceber a esse. Além disso, as imposições da cultura consumista demandam a hiperatividade, exigindo prontidão no agir. As pessoas agem sem necessariamente pensar, pois, caso não o façam, são invadidas pela angústia de não estar produzindo, de não estar rendendo seu tempo (BIRMAN, 2012).

Percebe-se que a noção de tempo e espaço mudou de forma considerável. Birman (2012) constata que hoje se vive na era da pressa, da intempestividade e das surpresas permanentes, o que acarreta importantes implicações. Considerando esta nova dimensão de temporalidade e o fato de que o psiquismo exige outro tempo para registrar simbolicamente as demandas, o autor considera que resta ao sujeito a descarga da excitabilidade via corpo ou via ato, impossibilitando-o de oferecer alternativas de destinos para as descargas 
psíquicas. Assim, o mal-estar decorrente do status quo contemporâneo é o do excesso, uma vez que as demandas se apresentam incessantemente para um sujeito cada vez mais fragilizado e desamparado. A dor sentida se mostra atrelada à dificuldade de acessar o outro e pedir ajuda, já que o apelo, em uma sociedade que exige performance, evidencia a falha e gera vergonha.

Percebe-se que, na emergência da dor, há uma materialização sensorial do desconforto, mesmo que esta dor seja da ordem do psíquico. A materialização da dor evidencia um sujeito-organismo, que, muitas vezes, busca um medicamento que o faça cessar tal sensação. Logo, o uso de psicofármacos encaixa-se, convenientemente, nas demandas da contemporaneidade, pois, ao atender os reclamos da dor e seu apagamento, não surge espaço para o sujeito implicar-se no que produz como psicopatologia.

Neste sentido, torna-se mandatória a referência ao DSM - Diagnostic and Statistical Manual of Mental Disorders, criado pela Associação Americana de Psiquiatria em 1952. Ao longo dos anos, diversas revisões e reformulações ocorreram no manual com o propósito de conceber uma única lógica classificatória ateórica e objetiva no campo da psicopatologia. Russo e Venâncio (2006) constatam que o pressuposto empiricista implicado nessa posição ateórica evidencia uma visão fisicalista das perturbações mentais, uma vez que estaria baseada em princípios de testabilidade e verificação, sendo os diagnósticos realizados a partir de critérios acessíveis à observação e à mensuração. Para os autores, a pesquisa experimental exigida nessa lógica está atrelada aos interesses da indústria farmacêutica, que investe em ensaios clínicos randomizados para a testagem de novos medicamentos visando o tratamento dos novos diagnósticos. Logo, o surgimento e a progressiva difusão de nomenclaturas diagnósticas permitiu, paulatinamente, a ascensão da psiquiatria biológica como vertente dominante no panorama psiquiátrico mundial. Entretanto, Dunker e Neto (2015) afirmam que a psiquiatria, ao se distanciar do território ambíguo e polifônico do sofrimento, do mal estar e da significação, aproxima-se cada vez mais de uma prática mecânica de medicalização de massas.

Considerando as manifestações psicopatológicas do contexto histórico atual, demarca-se que a psicanálise pode contribuir não somente para a compreensão da singularidade desses fenômenos psicopatológicos, mas, principalmente, ofertar modalidades de escuta e de intervenção a partir de suas efetivas possibilidades de cuidado, as quais exigem um exercício inegável de sensibilidade e de ética por parte do analista. A escuta analítica como exercício ético no campo da alteridade situa-se na contramão das imposições contemporâneas, oferecendo um espaço para o trabalho com a singularidade do sujeito, seus desejos e padecimentos, diferentemente de convocá-lo à performance e à massificação cultural. Nesta concepção, a dor psíquica não deve ser "exorcizada", mas, sim, acolhida e escutada na dimensão do valor atribuído à implicação do próprio sujeito na produção de seu padecimento. A autonomia e a liberdade não são "receitadas" no saber prévio sobre o sujeito, mas construídas e/ou recuperadas no encontro analítico, a partir de um intenso e ativo processo de autoconhecimento do sujeito que padece.

Adentra-se o século XXI e se constata o recurso às modalidades de enfrentamento da psicopatologia que atualizam permanentemente práticas já conhecidas de prioridade à cessação da dor. 0 paradigma organicista e experimental ganha espaço via intensa medicalização das experiências humanas. Neste circuito que deixa o sujeito à margem, surge e se sustenta a psicanálise e sua ética de priorizar a fala de um sujeito singular na construção de suas possibilidades de autonomia e liberdade.

\section{CONSIDERAÇÕES FINAIS}

É possível constatar, ao longo dos séculos, que o homem se empenhou em encontrar axiomas sobre si mesmo e sobre o mundo que o circunda. Neste processo de construção de conhecimento, houve avanços e retrocessos. As concepções sobre psicopatologia oscilaram entre as diversas dimensões apresentadas, ocorrendo, na contemporaneidade, um retorno à valorização das explicações etiológicas de cunho anatomofisiológicas. 
Evidencia-se um predomínio da epistemologia organicista, a qual, ao propor olhar para o organismo, acaba esquecendo-se do sujeito. A humanidade é provocada em seu domínio decorrente do saber ao ser confrontada com outras modalidades de conceber o mundo e o sujeito. Ao ser descentrado via proposições de Galileu, Darwin e Freud o sujeito, por vezes, ataca o conhecimento como forma de evitar a desacomodação gerada. Especialmente no campo da saúde mental, o que "escapa" ao dito normal, parece provocar ainda mais dificuldades. A loucura, associada à desrazão precisou por muito tempo ficar "escondida" em manicômios. O desamparo provocado pela constatação do não saber gera a necessidade, outrora vigente, de encontrar certezas no mundo material.

Inegavelmente, a infindável busca pela verdade absoluta é um ideal inalcançável. A complexidade que envolve a definição de psicopatologia não recomenda a opção por uma conceituação restrita e homogênea, sob o risco de, ingenuamente, desconsiderar as especificidades de diferentes e diversos saberes. A própria busca pela praticidade diagnóstica - por meio dos manuais classificatórios em psicopatologia, ditos ateóricos - não deixa de ter uma ideologia que os sustenta, uma vez que são voltados para o pragmatismo e para uma visão diagnóstica a partir do observável e quantificável no comportamento. A visão descritiva de patologia não pode ser confundida com a compreensão dinâmica de um padecimento.

A partir do percorrido histórico retratado neste artigo, enfatiza-se a impossibilidade de desconsiderar as implicações subjacentes aos "critérios" que definem o normal e o patológico. Trata-se de não ignorar que o sujeito é multifacetado e, portanto, não pode ser reduzido a apenas uma de suas dimensões, principalmente quando se abarcam questões acerca do sofrimento humano.

Recebido em: 15 de maio de 2015. Aprovado em: 13 de novembro de 2015.

\section{REFERÊNCIAS}

ALBERTI, S.; FULCO, A. P. M. Um estudo, uma denúncia e uma proposta: a psicanálise na interlocução com outros saberes em saúde mental, como avanço do conhecimento sobre o sofrimento psíquico. Revista Latinoamericana de Psicopatologia Fundamental, n. 4, v. 8, 2005, p. 721-737.

BERLINCK, M. T. Psicopatologia Fundamental. São Paulo: Escuta, 2008.

BIRMAN, J. O sujeito na contemporaneidade. Rio de Janeiro: Civilização Brasileira, 2012.

CECCARELLI, P. R. O sofrimento psíquico na perspectiva da psicopatologia fundamental. Psicologia em Estudo, n. 3, v. 10, 2005, p. 471-477.

CHERUBINI, K. G. Modelos históricos de compreensão da loucura. Da Antigüidade Clássica a Philippe Pinel. Jus Navigandi, (on line), n. 1135, v. 11, 2006. Disponível em: <http://www.egov.ufsc.br/portal/sites/default/files/anexos/12432-12433-1-PB.pdf>. Acesso em: 21 out. 2015.

DOCKHORN, C.; MACEDO, M. A complexidade dos tempos atuais: reflexões psicanalíticas. Revista Argumento Psicologia, n. 54, v. 26, 2008, p.217-224.

DUNKER, C. I. L.; NETO, F. K. Psicanálise e saúde mental. Porto Alegre: Criação Humana, 2015.

FOUCAULT, M. A história da loucura na Idade Clássica. São Paulo, SP. Editora Perspectiva, 1978.

FREUD, S. A moral sexual 'civilizada' e a doença nervosa dos tempos modernos (1908). Rio de Janeiro: Imago, 1996. (Ed. standard brasileira das obras completas, 9).

Dois verbetes de enciclopédia (1922-1923). Rio de Janeiro: Imago, 1976. (Ed. standard brasileira das obras completas, 18).

O mal-estar na civilização (1929-1930). Rio de Janeiro: Imago, 1996. (Ed. standard brasileira das obras completas, 21).

FULGÊNCIO, L. O abandono da hipnose e a leitura metapsicológica dos sintomas. Revista Percurso, n. 21, v. 1,1998 , p. 59-66.

GABBAY, R.; VILHENA, J. O sujeito da loucura, Revista Latinoamericana de Psicopatologia Fundamental, n. 7, v. 2, 2010, p. 40-53.

LAPANCHE, J.; PONTALIS, J. B. Vocabulário de Psicanálise. 3. ed. São Paulo: Martins Fontes, 2000. 
PEREIRA, M. E. C. Kraepelin e a questão da manifestação clínica das doenças mentais. Revista Latinoamericana de Psicopatologia Fundamental, n. 1, v. 12, 2009, p. 161-166.

. Pinel - a mania, o tratamento moral e os inícios da psiquiatria contemporânea. Revista Latinoamericana de Psicopatologia Fundamental, n. 3, v. 7, 2004, p. 113-116.

PESSOTTI, I. A loucura e as épocas. Rio de Janeiro: Editora 34, 1994.

RODRIGUES, A. C. T. Karl Jaspers e a abordagem fenomenológica em psicopatologia. Revista Latinoamericana de Psicopatologia Fundamental, n. 4, v. 8, 2005, p. 754-768.

ROUDINESCO, E. Medicina, psiquiatria e psicanálise: semiologia do sujeito. In: Em defesa da psicanálise: ensaios e entrevistas. Rio de Janeiro: Jorge Zahar, 2005, p. 215-224.

RUSSO, J.; VENÂNCIO, A. T. Classificando as pessoas e suas perturbações: a "revolução terminológica" do DSM III. Revista Latinoamericana de Psicopatologia Fundamental, 9(3): 460- 83. 2006.

SILVEIRA, L. C.; BRAGA, V. A. B. Acerca do conceito de loucura e seus reflexos na assistência de saúde mental. Revista Latino-Americana de Enfermagem, n. 4, v. 13, 2005, p. 591-595.

VOLICH, R. M. Psicossomática. São Paulo: Casa do Psicólogo, 2000.

\section{Fernanda Cesa Ferreira da Silva Moraes}

fernanda.cesa@yahoo.com.br

Mônica Medeiros Kother Macedo

monicakothermacedo@gmail.com 